\title{
The pattern of Phosphate transporter 1 genes evolutionary divergence in Glycine max L.
}

\author{
Chengming Fan ${ }^{1}$, Xu Wang ${ }^{1}$, Ruibo $\mathrm{Hu}^{2}$, Yahui Wang ${ }^{3}$, Chaowen Xiao ${ }^{1}$, Ying Jiang ${ }^{1}$, Xiaomei Zhang ${ }^{1}$, \\ Changying Zheng ${ }^{3}$ and Yong-Fu Fu ${ }^{1 *}$
}

\begin{abstract}
Background: The Phosphate transporter 1 (PHT1) gene family has crucial roles in phosphate uptake, translocation, remobilization, and optimization of metabolic processes using of Pi. Gene duplications expand the size of gene families, and subfunctionalization of paralog gene pairs is a predominant tendency after gene duplications. To date, experimental evidence for the evolutionary relationships among different paralog gene pairs of a given gene family in soybean is limited.
\end{abstract}

Results: All potential Phosphate transporter 1 genes in Glycine max L. (GMPHT1) were systematically analyzed using both bioinformatics and experimentation. The soybean PHT1 genes originated from four distinct ancestors prior to the Gamma WGT and formed 7 paralog gene pairs and a singleton gene. Six of the paralog gene pairs underwent subfunctionalization, and while GmPHT1;4 paralog gene experienced pseudogenization. Examination of long-term evolutionary changes, six GmPHT1 paralog gene pairs diverged at multiple levels, in aspects of spatio-temporal expression patterns and/or quanta, phosphates affinity properties, subcellular localization, and responses to phosphorus stress.

Conclusions: These characterized divergences occurred in tissue- and/or development-specific modes, or conditional modes. Moreover, they have synergistically shaped the evolutionary rate of GMPHT1 family, as well as maintained phosphorus homeostasis at cells and in the whole plant.

Keywords: Phosphate transporter 1, Gene duplication, Gene divergence, Phosphorus homeostasis, Evolution, Glycine max L.

\section{Background}

To adapt to challenging environments, plants have developed dramatic modifications in morphological, physiological, biochemical and molecular processes. Gene duplications are widespread in plant genomes, having accumulated a wealth of genetic raw materials to meet the selection pressures of new environmental conditions [1-5]. After gene duplications, there are several possible fates for duplicated genes (or paralogs), which include subfunctionalization through purifying selections $(\mathrm{Ka} / \mathrm{Ks}<1)[6]$, neofunctionalization through positive selections $(\mathrm{Ka} / \mathrm{Ks}>1)$ [7], pseudogenization [8], and loss in

\footnotetext{
* Correspondence: fuyongfu@caas.cn

${ }^{1}$ MOA Key Lab of Soybean Biology (Beijing), National K'ey Facility of Crop Gene Resource and Genetic Improvement, Institute of Crop Sciences, Chinese Academy of Agricultural Sciences, 12 Zhongguancun Nandajie, Haidian District, Beijing 100081, China

Full list of author information is available at the end of the article
}

genome (fractionation) [9-11]. Subfunctionalization is the predominant paralog outcome following duplications [12]. It reduces the fitness cost of gene duplication by buffering dosage imbalances, as well as maintaining the functional requirements of the ancestral locus [13].

In plants, phosphorus is one of three primary mineral nutrients. It is second most limiting macronutrient for optimal growth, due to the relatively large amounts of Pi required by plants, the limited amount of available phosphorus (orthophosphate, $\mathrm{Pi}$ ), and the poor mobility of phosphorus in soil $[14,15]$. Plant uptake of Pi from soil relies heavily upon the phosphate transporter 1 family (PHT1) [16]. PHT1 genes code for plasma membrane proteins, which contain 12 transmembrane domains. The PHT1 proteins are functionally involved in Pi uptake from the soil, Pi translocation across plant tissues, and $\mathrm{Pi}$ remobilization from senescent organs (Review in $[14,17,18]$ ). Homologous genes of PHT1 have been identified in a wide range of 
species, and they share conserved functions in the Pi uptake (Additional file 1) [14] and variable Pi affinity [19-22].

The soybean has experienced the Gamma whole genome triplication (Gamma WGT) 130 to 240 million years ago (mya), the legume WGD (Legume WGD, 58 mya), and the Glycine WGD in the Glycine lineage (Glycine WGD, $\sim 13$ mya) $[23,24]$. As a result, in the present soybean genome, about $75 \%$ of the genes have multiple paralogs $[23,25]$. Approximately $50 \%$ of these paralogs were differentially expressed and underwent subfunctionalization [12], possibly contributing to phenotypic variation in polyploids [3].

Many PHT1 genes have functionally identified in many plants, but they are studied as an individual. This was a limiting step for both further functional characterization of PHT1 family as a whole and genetic evolution analysis of them in relation to low Pi environment adaptations. In this study, 15 GmPHT1 (Glycine max PHT1) family paralogs from soybean were identified. Based on data from spatio-temporal expression profiles, functional characterizations in a heterologous yeast system and subcellular localizations, we propose fates of paralogs of soybean PHT1 were subfunctionalization. These results provided a strong basis for function analysis and evolution of gene families.

\section{Results}

Identification, phylogenetic relationship and promoters of soybean PHT1 genes

Fourteen soybean PHT1 genes with full length sequence were found [26,27]. In addition, a syntenic analysis using the PGDD or CoGe databases identified one potential pseudogene (Glyma13g18420), which had a truncated open reading frame length (ORF) of $444 \mathrm{bp}$. This potential pseudogene, which was determined to be masked, has not been previously identified $[21,26,28]$. For an unified nomenclature for the soybean PHT1s (Additional file 2), fifteen soybean PHT1 genes were renamed as GLYma;Pht1;1 through GLYma;Pht1;15 according to the Commission for Plant Gene Nomenclature, and abbreviated as GmPHT1;1 through 15 in the following content.

These 15 PHT1 genes are dispersed across eight chromosomes and form 7 paralog gene pairs and one singleton (Figure 1A). These paralog gene pairs shared 93.5 97.1\% in sequence (Additional file 3A) and similar gene structures (Additional file 3B). For example, both GmPHT1;8 and GmPHT1;9 have 3 exons, both GmPHT1;3 and GmPHT1;14 are composed of 2 exons, while the others only contain one. However, an extra intron in $5^{\prime}$-UTRs of GmPHT1;1, GmPHT1;4 and GmPHT1;5 was identified (Additional file 3B).

To identify the phylogenetic relationship of the soybean PHT1 genes with full length sequence, a neighborjoining tree was reconstructed based on the multiple sequence alignment (Additional file 4). The PHT1 family was monophyletic [29] and can be grouped into four subfamilies in the angiosperm: the subfamily I is composed of PHT1 genes induced by arbuscular mycorrhizal fungi (AMF), subfamily II genes are from both monoand dicotyledonous species, subfamily III are exclusively from dicotyledonous species, and subfamily IV are exclusively from monocotyledonous species [26,30]. Furthermore, the subfamily II was closely related to the homologs from the fungi by high bootstrap value (Additional file 4), indicating it was present before the occurrence of terrestrial plant and an older evolutionary lineage. In the soybean, fourteen PHT1 genes were clustered into three subfamilies: subfamily I, subfamily II and subfamily III (Additional file 4) [21,26].

The paralog gene pair's promoter region sequence similarities are lower than their CDS sequences (Additional file 3A). Many similar cis-acting regulatory DNA elements, which are relative to the nodulin, root, flower, leaf, seed, abiotic or biotic stress, sugar and hormone (Additional file 5A), can be found in promoter regions of 14 PHT1 genes according to the PLACE results [31]. For example, the cis-elements relative to the root-specific (ROOTMO TIFTAPOX1) and nodule-specific (NODCON1GM and NODCON2GM) are present in 14 soybean PHT1 promoters (Additional file 5A). Except GmPHT1;9 promoter, other soybean PHT1 promoters contain phosphate starvation responsive cis-element (PIBS). And GmPHT1;9 promoter did not embody PIBS motif but a variant PIBS motif (76\% similarity to PIBS) (Additional file 5A). The differences in common cis-elements across these promoter regions include both their number and their distance from the starting code (Additional file 5A). That indicated the number of cis-elements and their distance from the transcription start sites affected response abilities of PHT1 to the environment.

\section{Soybean PHT1 genes originated from four ancestors prior to the Gamma WGT event}

The average synonymous substitution rate $(K s)$ of homologous blocks is a function of genomic evolutionary events that occurred since two homologous blocks diverged from a common ancestor [25,32]. The modern soybean genome has undergone Gamma WGT (Ks > 1.5), Legume WGD ( $K s \sim 0.3$ to 1.5 ) and Glycine WGD (Ks $\sim 0$ to 0.3 ) [24,25]. To analyze the soybean PHT gene duplication relationship, Medicago truncatula, which experienced the Gamma WGT event and Legume WGD event [33], was selected as the reference gene order and 9 Medicago PHT1s were identified (Additional file 5B).

Based on the analysis of homologous genomic regions, seven paralog GmPHT1 gene pairs fell into 14 syntenic blocks and diverged after the Glycine WGD event. This was based on each pair of blocks having collinearity, with the average $K s$ ranging from 0.19 to 0.25 (Figure 1A, 


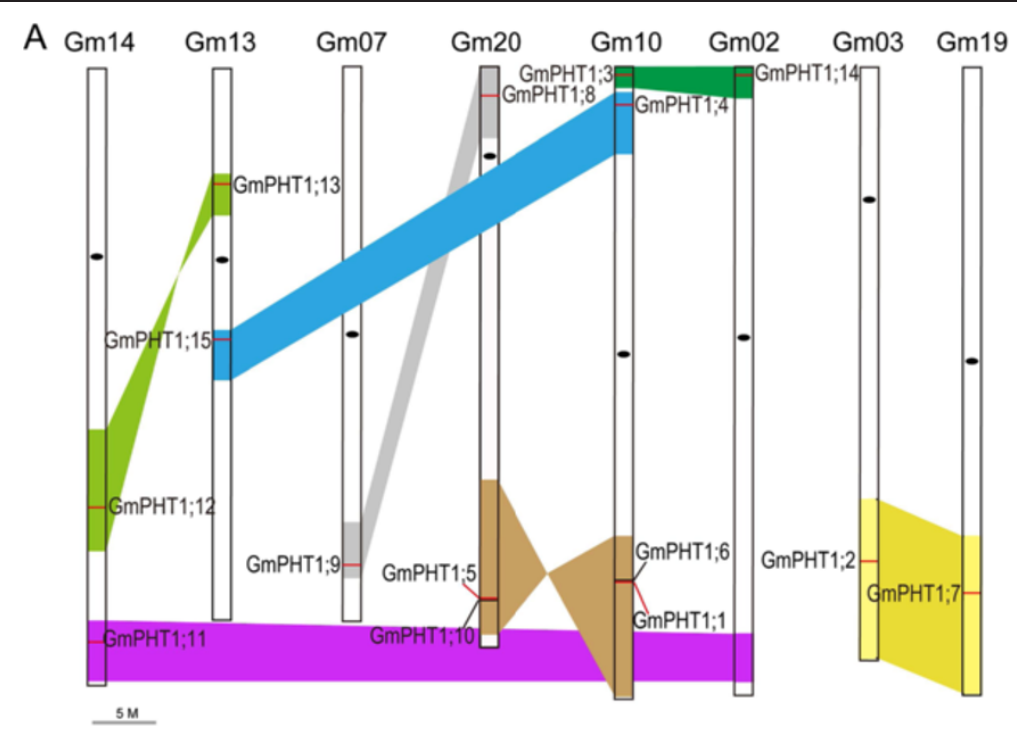

B

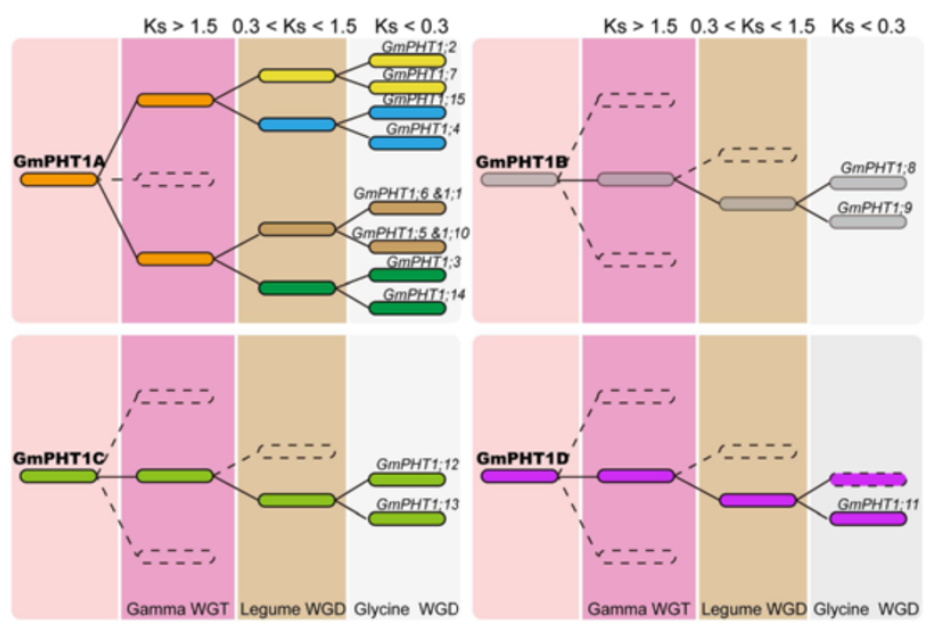

Figure 1 The evolution of the GmPHT1 gene family. A, Syntenic relationships among homologous blocks carrying the 15 GmPHT1 sequences after the Glycine WGD event. Similar colored blocks imply homology, the short red lines within these blocks show the location of GmPHT1s, and the black oval is the centromere. GmPHT1;15 is the pseudogene and the paralog gene of GMPHT1;11 was lost. B, The evolutionary model for GMPHT1-containing genomic blocks in the process of the soybean genome evolution, indicating GmPHT1s originated from four independent ancestors. Different backgrounds depict different whole genome duplication events. The colored blocks imply homology based on the average Ks values. The paralog gene of GMPHT1;11 was lost in the dotted block dotted, although other genes are collinear with the block containing GMPHT1;11. The detailed collinearity relationships are shown in Additional file 5C.

Additional file 5C). Although the paralog gene of GmPHT1;11 was lost in the syntenic block of chromosome 2, the block containing GmPHT1;11 underwent Glycine WGD events (Figure 1A and Additional file 5C). Because the homologous block containing MtPHT4 on Chromosome 5 in $M$. truncatula had a collinearity with the block harboring GmPHT1;11 (Additional file 5B). With the exception of the WGD duplication, the ancestor of two paralog gene pairs, GmPHT1;1/5 and GmPHT1;6/10, experienced tandem duplication before the Legume WGD event. Because the blocks embodying GmPHT1;1/6 and GmPHT1;5/10 had a collinearity with the block containing two tandem genes, MtPHT5 and 7, on Chromosome 1 of M. truncatula (Additional file 5B).

Based on the average $K s$ values for the homologous blocks (Additional file $5 \mathrm{C}$ ), the evolution history of all 15 PHT1 genes was predicted. These PHT1 genes were categorized into four subgroups, GmPHT1A through D (Figure 1B). For example, GmPHT1A included eight syntenic blocks, which represented five paralog gene pairs of PHT1 genes, GmPHT1;2/7, GmPHT1;4/15, GmPHT1;1/5, GmPHT1;6/10 and GmPHT1;3/14. Both GmPHT1B and GmPHT1C contained two syntenic blocks and each contained one paralog gene pair of PHT1 genes, GmPHT1;8/9 


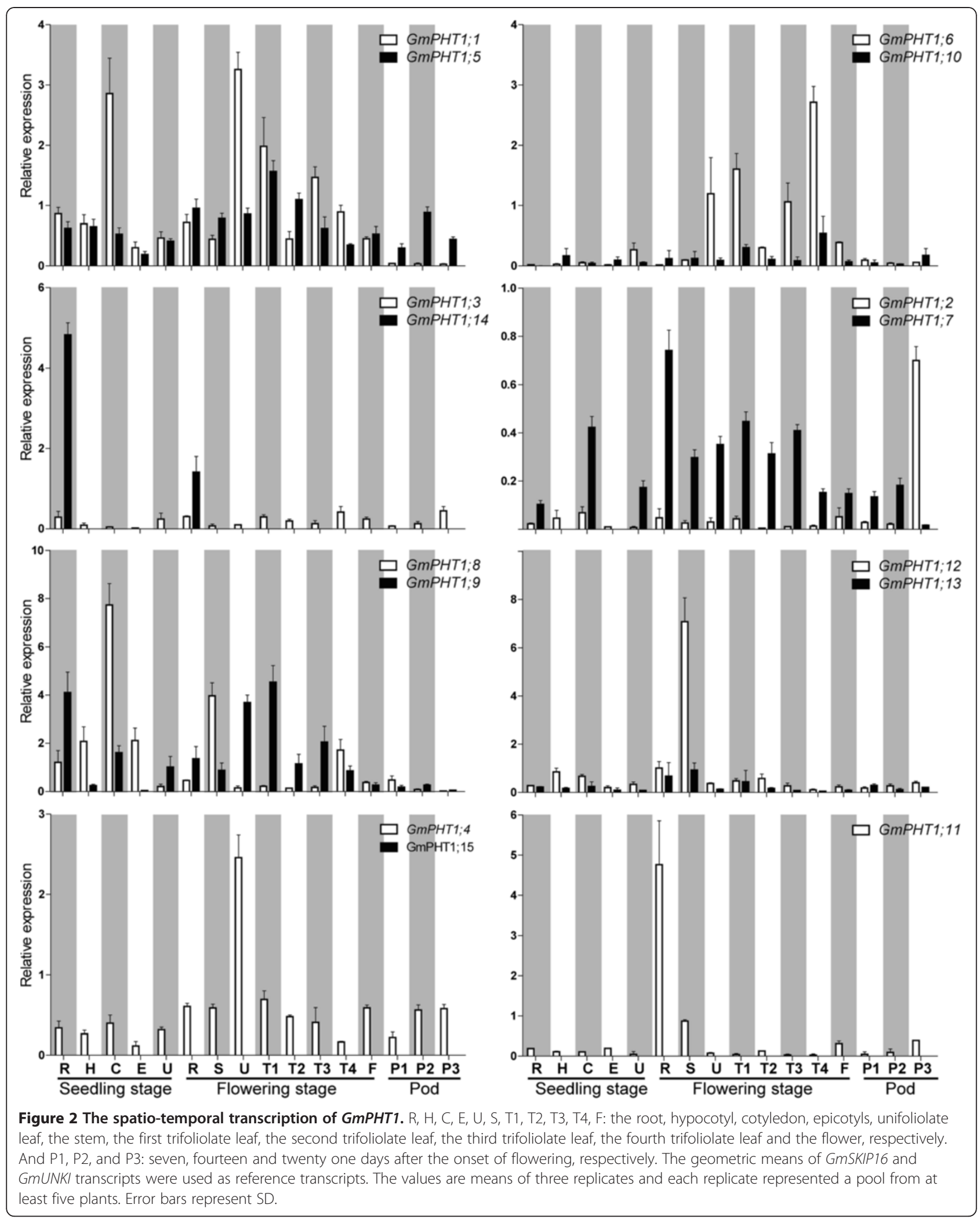


and GmPHT1;12/13, respectively. GmPHT1D group was made up of two syntenic blocks and contained the GmPHT1;11 gene. These results indicated the soybean PHT1 gene family originates from four distinct ancestors, at least prior to the Gamma WGT event.

\section{Divergence of GmPHT1 expressions in different tissues and in developmental stages}

Duplicated genes typically exhibit increased expression divergence, thus gene expression changes shape evolutionary rates of proteins and re-establish the gene balance after duplication [34]. Based on the spatio-temporal expression of GmPHT1 genes through real time quantitative RT-PCR (qRT-PCR), most paralog gene pairs coexpressed in 16 tissues (Figure 2, Additional file 5D). However, two paralog gene pairs demonstrated obvious expression pattern differences. GmPHT1;14, was only expressed roots, but the expression of its paralog gene, GmPHT1;3, was detected at low level in all samples. And the GmPHT1;2 paralog gene, GmPHT1;7, did not express in hypocotyls and epicotyls at the seedling stage.

The expression levels among paralog gene pairs demonstrated clear divergence (Figure 3). Among the six paralog gene pairs, 80 pairs of co-expression values were obtained from 16 tissues. The overall expression levels difference were as follows, $\sim 24 \%$ had between a 1 to 2 fold change, $\sim 54 \%$ between a 2 -to 10 fold change, and $\sim 22 \%$ had more than a 10 -fold change. Moreover, genebiased expression levels between a paralog gene pair were observed. For example, one paralog gene pair, GmPHT1;2 and GmPHT1;7 displayed expression biased to GmPHT1;2 in 15 tissues, only different in the pods after 21 FAD.
In addition, expressions were biased to GmPHT1;12 between the paralog gene pair, GmPHT1;12 and GmPHT1;13 (Figure 3).

\section{GmPHT1 genes differential response to the Pi stress}

Plant root performance dependents directly on Pi availability in soil [35]. Pi stress induces most of the known PHT1s genes (Review in $[14,17,18])$. To investigate GmPHT1 responses under low $\mathrm{Pi}(\mathrm{Pi}=1 \mu \mathrm{M})$ stress conditions, soybean PHT1 gene expressions were evaluated in the root, stem and leaf, at the vegetative stage (Figure 4). Compared with expressions under high $\mathrm{Pi}(\mathrm{Pi}=500 \mu \mathrm{M})$ conditions, all soybean PHT1 genes were up-regulated in roots under the low $\mathrm{Pi}$ condition. Divergent expressions of some paralogs were observed in stem or leaf tissues (Figure 4). Except GmPHT1;4, 7 and 12, transcriptions of other soyben PHT1 genes were down-regulated in stems under low Pi conditions. Additionally, expressions of GmPHT1;3 and 8 were induced by the high Pi condition in leaves.

In addition to under the low $\mathrm{Pi}$ condition, the responses of GmPHT1 genes to a series of Pi concentrations in the roots were employed to investigate the expression divergence of the paralog gene pairs (Figure 5). Compared with those under the low $\mathrm{Pi}(\mathrm{Pi}=1 \mu \mathrm{M})$ condition, expressions of all $13 \mathrm{GmPHT1}$ genes were significantly supressed in the roots under the $\mathrm{Pi}=10 \mu \mathrm{M}$ condition except GmPHT1;6. And when the external Pi concentration was more than $10 \mu \mathrm{M}$, the range of expressions were very narrow except GmPHT1;2, GmPHT1;3, GmPHT1;12 and $G m P H T 1 ; 13$. That indicated most paralog gene pairs showed the similar responses to the external $\mathrm{Pi}$ in the

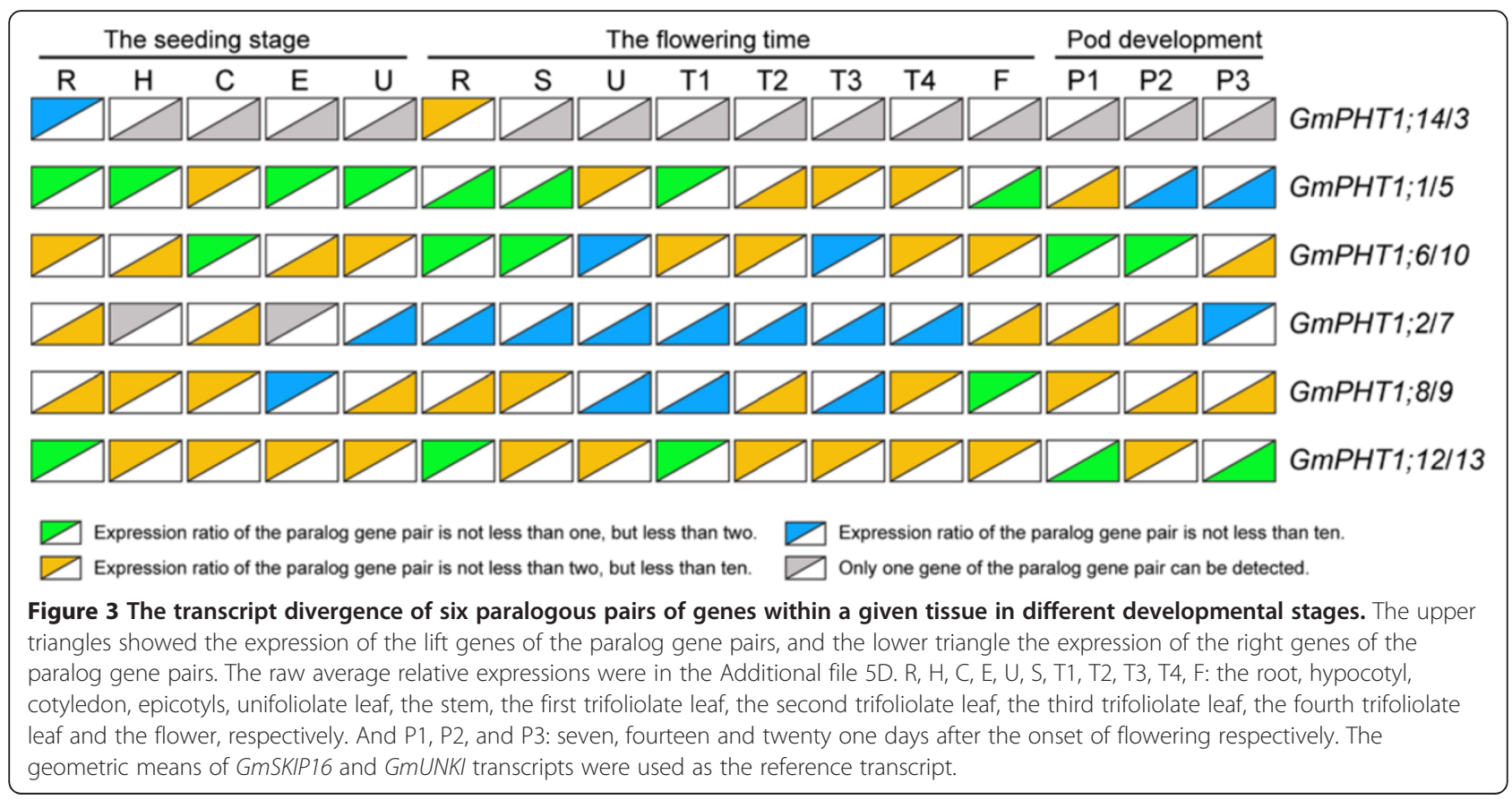




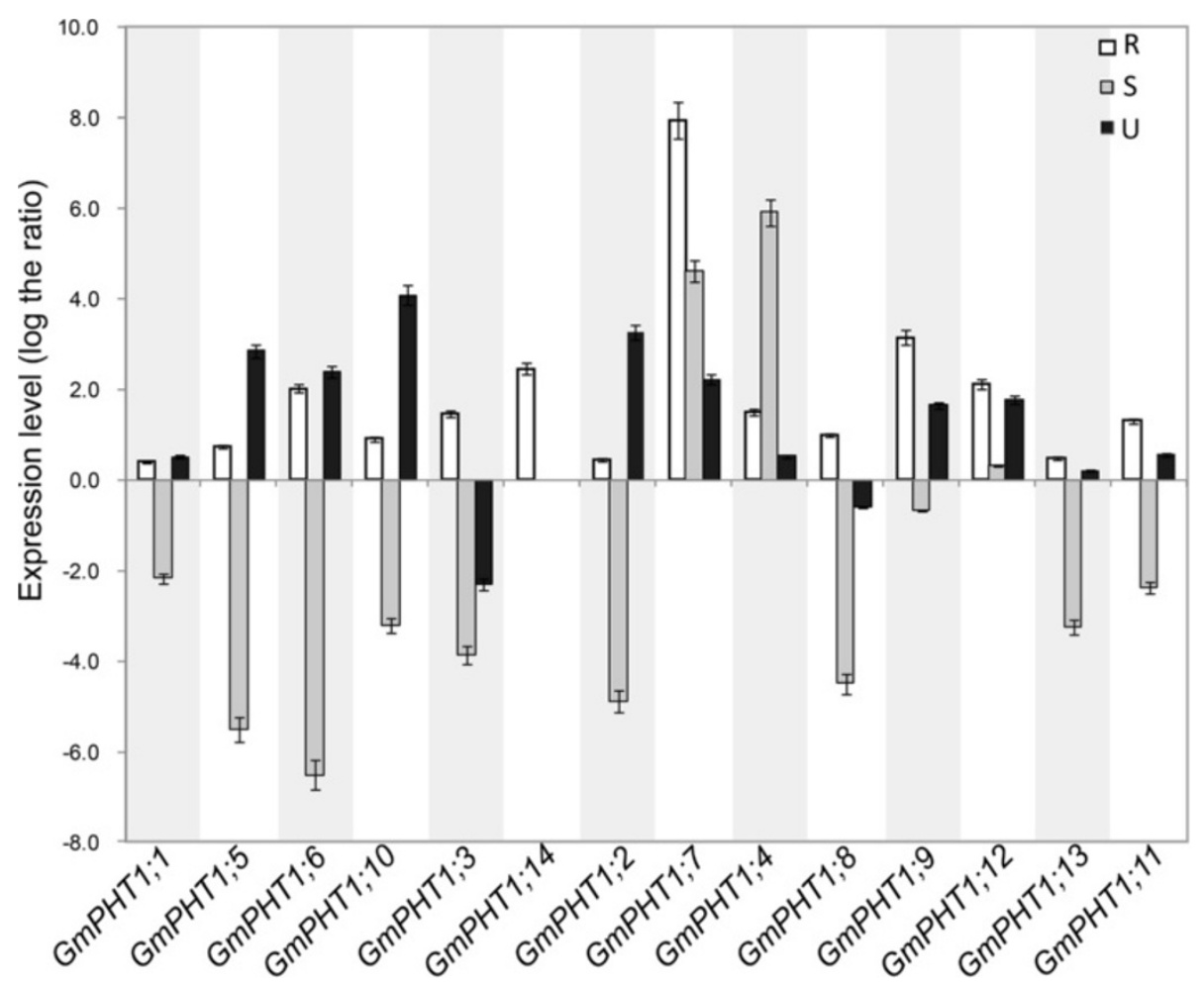

Figure $4 \mathrm{GmPHT1}$ transcription in the response to the low $\mathrm{Pi}(1 \mu \mathrm{M})$ stress. At least five individual plants per treatment were harvested when the unifoliolate leaves fully expanded. The transcript abundance of GmPHT1 genes in the roots (R), stems (S) and unifoliolate leaves $(U)$ were shown using the expression of the $500 \mu \mathrm{M}$ Pi treatment group as a control. The geometric means of GmSKIP16 and GmUNKI transcripts were used as the reference transcript. The values are means of three replicates and each replicate represented a pool from at least five plants. Error bars represent SD.

root except GmPHT1;2/7 and GmPHT1;3/14. And under the high-Pi condition, the transcriptions of GmPHT1;2 and GmPHT1;3 were induced, but the strength were lower than under the low Pi condition (Figure 5). That suggested that GmPHT1;2 and GmPHT1;3 may contributed to Pi tolerance in soybean.

\section{Divergence in the Pi transport activities of GmPHT1 in yeast}

To investigate the divergence of 14 soybean PHT1s in the Pi transport ability, the abilities of heterologous complementation of yeast double mutant (PAM2, $\Delta$ pho84 $\Delta$ pho89) [36] were tested on the nutrition defect media (Additional file 6). The resulting sequences were confirmed by sequencing and cloned into pYES-DEST52 drive by GAL1 promoter.

As Figure 6 shown, only one paralog gene pairs, GmPHT1;6/10, showed difference of complementation ability. And PAM2 cells carrying GmPHT1;1, GmPHT1;2, GmPHT1;5, GmPHT1;7, and GmPHT1;10 grew well on the induced modified SD media (the carbon source is galactose) under the low $\mathrm{Pi}$ condition, whereas PAM2 cells harboring other $9 \mathrm{GmPHT1}$ and the empty vector did not grow normally under the same conditions. This data suggested that GmPHT1;1, GmPHT1;2, GmPHT1;5, GmPHT1;7, and GmPHT1;10 may be high-affinity phosphate transporters and others were lower-affinity ones.

Kinetic parameters $(\mathrm{Km})$ can display the affinity ability of the PHT1 proteins for transporting Pi. Subsequent ${ }^{32} \mathrm{Pi}$ uptake assays were employed to further confirm the different affinity of GmPHT1 and to analyze $K_{m}$ values of Pi uptake of 4 paralogous pair transporters (Figure 7). The paralogous gene pairs also displayed divergence on the affinity for Pi. For example, GmPHT1;1 had a $K_{m}$ of $68.9 \mu \mathrm{M}$, while its papralogous transporter GmPHT1;5 had a $K_{m}$ of $243.9 \mu \mathrm{M}$; the $K_{m}$ of $\mathrm{GmPHT} 1 ; 12$ was $505.1 \mu \mathrm{M}$, whereas the $K_{m}$ of GmPHT1;13 was $363.6 \mu \mathrm{M}$, both of them were low affinity transporters.

\section{Divergence on the subcellular localization of GmPHT1 proteins}

The PHT1 protein in plants primarily localizes to the plasma membrane $[14,20,37]$. Under Pi stress they are targeted to endocytic compartments [38]. To analyze subcellular localization of GmPHT1 proteins, we tagged the GmPHT1 proteins with yellow fluorescence protein (YFP) at their C-terminal. With the exception of GmPHT1;8 and 

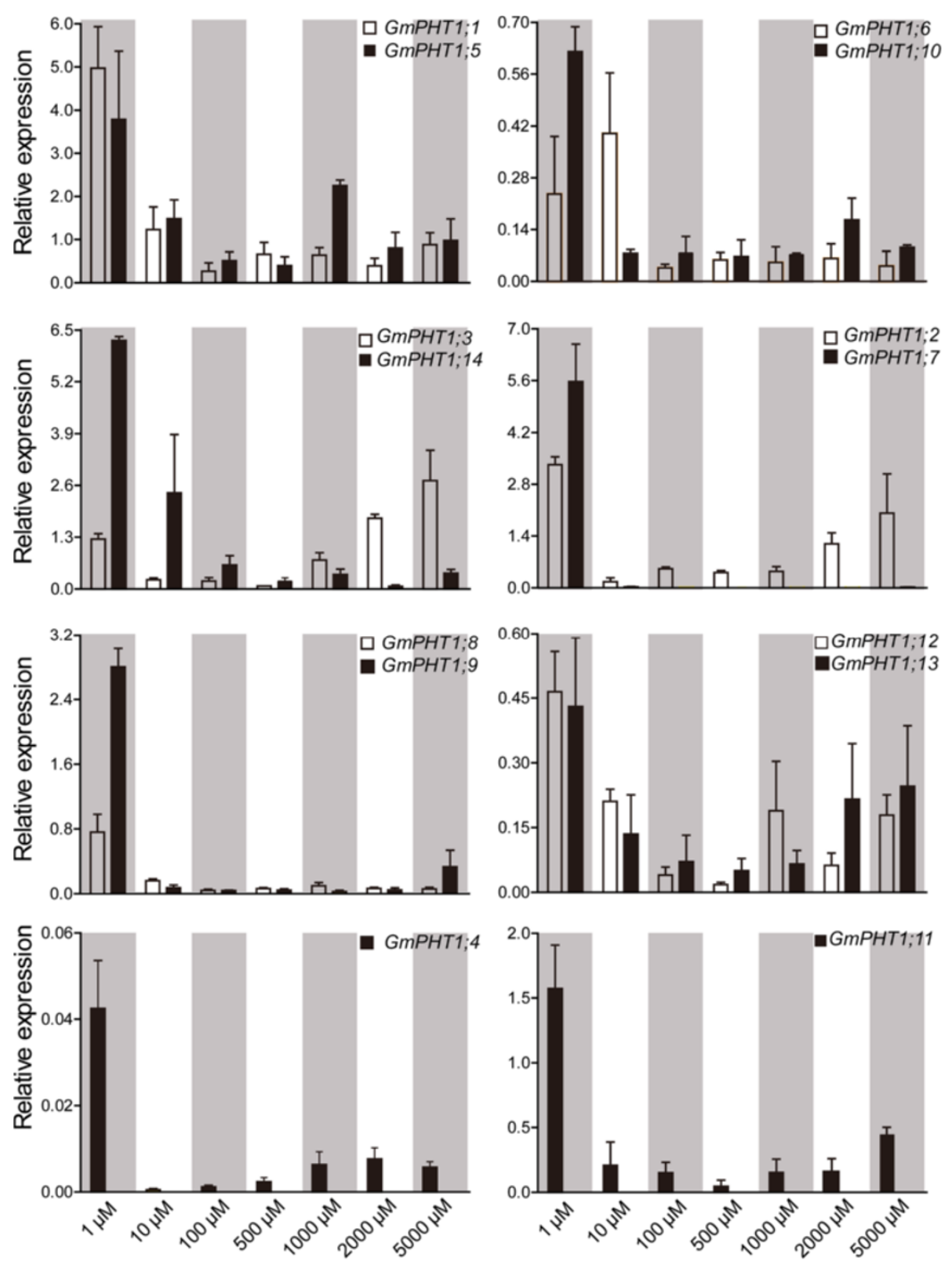

Figure $5 \mathrm{GmPHT1}$ transcription in the root is affected by external Pi concentration. Roots of at least five individual plants per treatment were harvested when the unifoliolate leaves fully expanded. Different paralogous pair genes were plotted in individual figures. The geometric means of GMSKIP16 and GmUNKI transcripts were used as the reference transcript. The values are means of three replicates and each replicate represented a pool from at least five plants. Error bars represent SD.

GmPHT1;10, twelve GmPHT1 proteins co-localized to the plasma membrane (Figure 8).

One exceptional case was the localization pattern of GmPHT1;8. Though no fluorescent signal of GmPHT1; 8-YFP was detected in the plasma membrane (Figure 9A), a strong signals in endoplasmic reticulum (ER) was detected. GmPHT1;8 co-localized to the ER in Arabidopsis mesophyll protoplasts along with ER-marker [39] (Figure 9B).
Another exception was GmPHT1;10 localization. Here, GmPHT1;10 fluorescent signals were detected both at the plasma membrane as well as outside of the plasma membrane (Figure 9C). These localization patterns were recapitulated in plasmolytic onion epidermal cells. Strong fluorescence was detected in cell walls, plasma membranes and Hechtian strands (Figure 9D). Moreover, paralog gene, GmPHT1;6, and another gene pair, GmPHT1;1 and 5, presented with strong signals only in the plasma membrane 


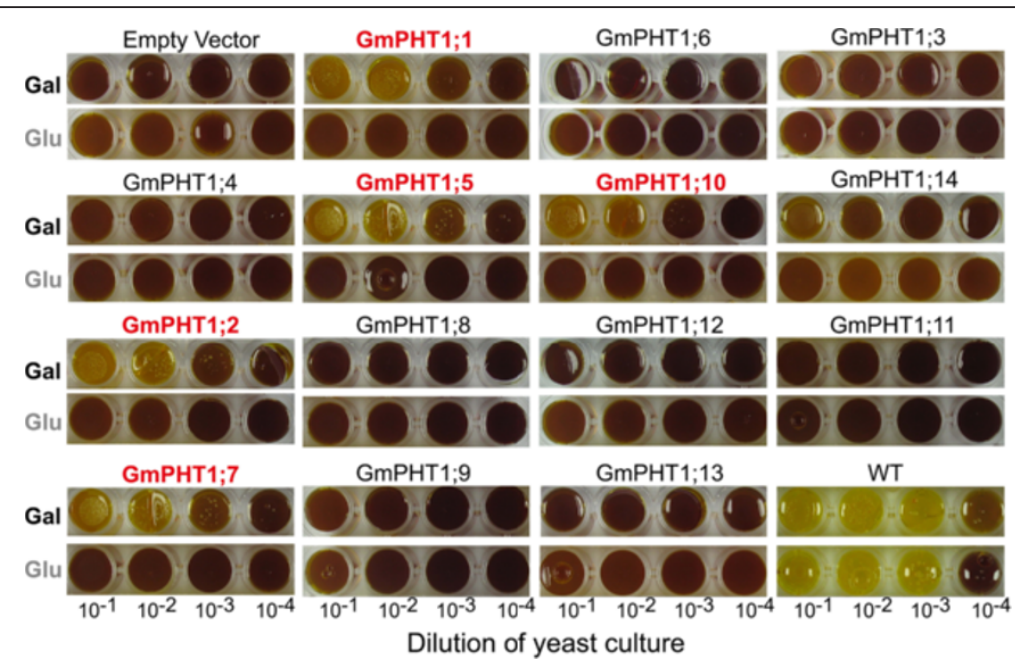

Figure 6 Complementation analysis of GmPHT1 genes in the yeast double mutant PAM2. Wild type (WT) and mutant (PAM2) yeast strains containing either an empty pYES-DEST52 vector (Empty vector) or pYES-DEST52 (bearing one of the GmPHT1 sequences). Serial dilutions were spotted onto a selective medium supplemented with low concentrations $(10 \mu \mathrm{M})$ of $\mathrm{Pi}$, with either glucose (Glu, non-induced medium) or galactose (Gal, induced medium) as the carbon source. Each spot represented $5 \mu$ yeast culture, diluted from a master culture, as indicated. Yellow color indicates the cell in the spots grew well. Images were captured after three days.

(Additional file 7). This pattern was a copy of that found in Medicago MtPT3 [20] and Arabidopsis Pht1;1 [37].

\section{Discussion}

Different lineages of PHT1 genes undergoing different nature selections during the plant evolutionary process Land plants only gain phosphorous from soil solutions through the root, and most PHT1 genes express and are induced by the Pi starvation or by AMF in the root $[16,40,41]$, indicating Pi uptake is heavily dependent on the phosphate transporter 1 family in the plant. In order to adapt the low-Pi environment and improve Pi uptake, two Pi uptake pathways have evolved under the nature selection. First, the direct $\mathrm{Pi}$ acquisition pathway acts through modifications of root architecture, root length and lateral root numbers [42-44]. The second pathway is symbiotic Pi uptake, which acts through plant/fungi interactions $[29,45]$.

Before the occurrence of the first terrestrial plant, which were present about 475 million years ago [46], the PHT1 subfamily II has been divergent based on the phylogenic tree (Additional file 4), indicating the direct Pi acquisition pathway was the main $\mathrm{Pi}$ acquisition pathway of ancient plants. About 460 million years ago, AMF occurred and may have played a crucial role in facilitating the colonization of land by plants most likely only consisted of plants on the bryophytic level [47]. And then the PHT1 subfamily I was diverged, suggesting the subfamily I is another older evolutionary lineage. Therefore, AMF have been symbionts of land plants for at least 450 million years old, and the symbiotic Pi uptake is an evolutionarily ancient Pi acquisition strategy for plant life on land $[29,48]$.

In the evolutionary process of plants, genome duplications were ancient and recurrent [49]. They provide the important raw genetic material to adapt to challenging environment and increase the diversity of plants. New genome sequences and improved analytical approaches are clarifying angiosperm evolution and revealing patterns of differential gene loss after genome duplication and differential gene retention associated with evolution of some morphological complexity [50]. According to the evolution of the PHT1 family, the members of PHT1 subfamily I and II, which are diverged eailier, were not expanded as expected in angiosperms compared with the subfamily III and IV. For example, In Arabidopsis, which is not host plant of AMF and experienced at least three polyploidy events [51], nine members of the PHT1 family were found, but no members of PHT1 subfamily I [52,53]. In Populus trichocarpa, experiencing at least two polyploidy events [54], PtPT10 and PtPT8 belong to the PHT1 subfamily I, and PtPT8 is a pseudogene [30]. In the rice, experiencing one polyploidy event [55], contain two nonredundant members of the PHT1 subfamily I, OsPT11 and OsPT13 [56,57]. And OsPT13 is conserved and special across monocotyledons [56]. In the soybean, undergoing three WGD events [23-25], three members of the PHT1 subfamily I, GmPHT1;11, 12 and 13, were found. GmPHT1;12 and GmPHT1;13, were a paralog gene pair arisen after the Glycine WGD event. And the GmPHT1;11 paralog gene was lost after the Legume WGD event and 

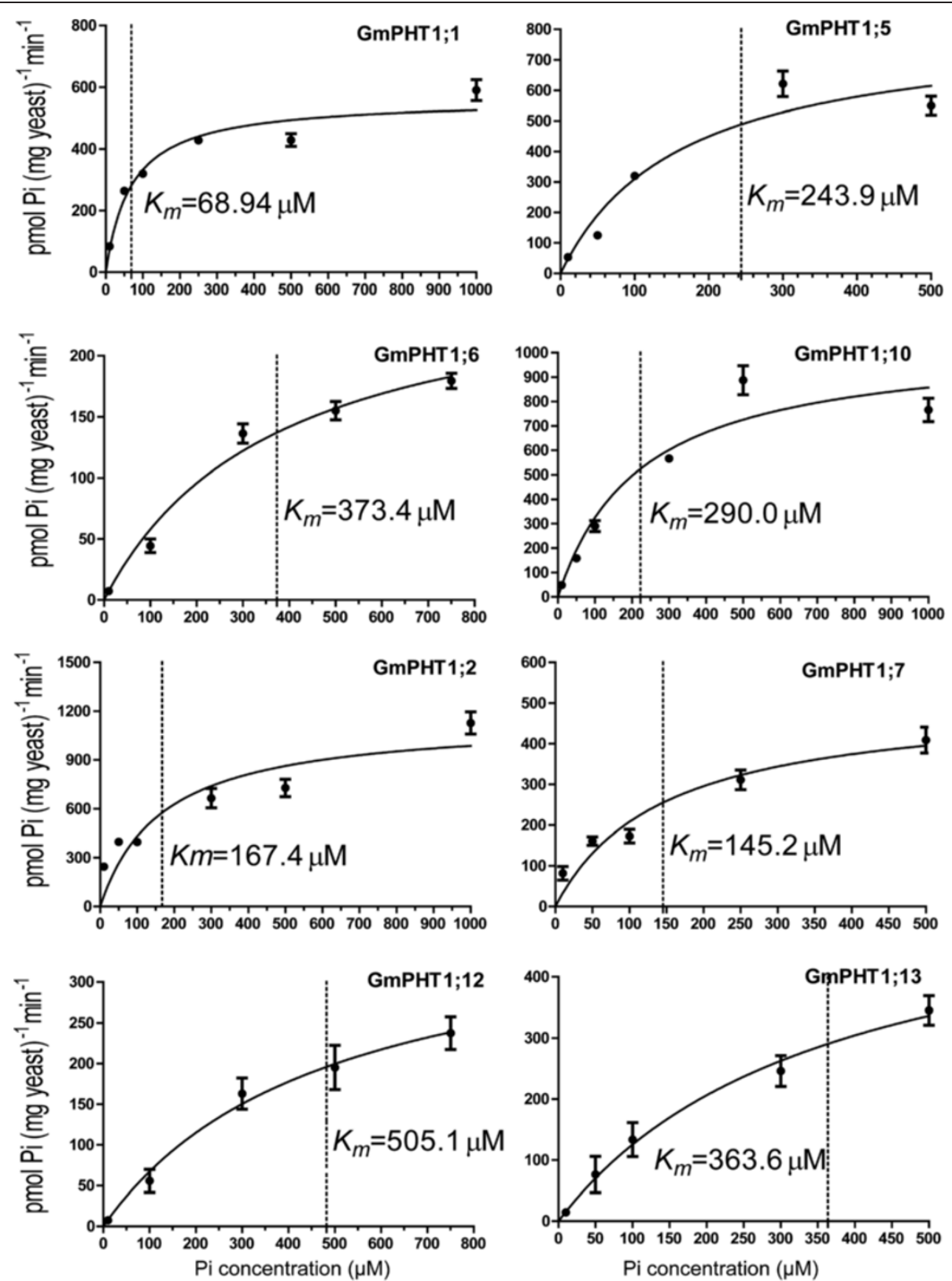

Figure 7 Radioactive phosphorus $\left({ }^{32} \mathrm{Pi}\right)$ uptake by PAM2 cells carrying a GmPHT1 gene. Each point represents the average and SD of at least three uptake experiments. The concentration of external Pi was $10 \mu \mathrm{M}, 50 \mu \mathrm{M}, 100 \mu \mathrm{M}, 300 \mu \mathrm{M}, 500 \mu \mathrm{M}$ or $1000 \mu \mathrm{M}$. Km values are indicated next to the dot lines and gained through GraphPad Prism 5.

then GmPHT1;11 became a singleton (Figure 1). Conversely, the GmPHT1-A experienced three rounds of WGD events and is composed of 9 members with whole coding sequences, plus one pseudogene (GmPHT1;15). For the PHT1 subfamily II, about two members can be found in each plants, while members of subfamily III or IV were expanded after gene duplication (Additional file 4). Taken together, different selection pressures retained different subgroups during the plant evolution.
Multiple divergences resulted in retention of paralogs from one gene family

Polyploidy is widespread and is a process that recurrently shaped eukaryotic genomes in plant. After genome duplication once fixed within species, the three possible fates of duplicated genes: neofunctionalization, subfunctionalization or nonfunctionalization [6-8,58]. If the $\mathrm{Ka} / \mathrm{Ks}$ value is more than 1.0, gene copies would undergo positive selection and have new functions. On 


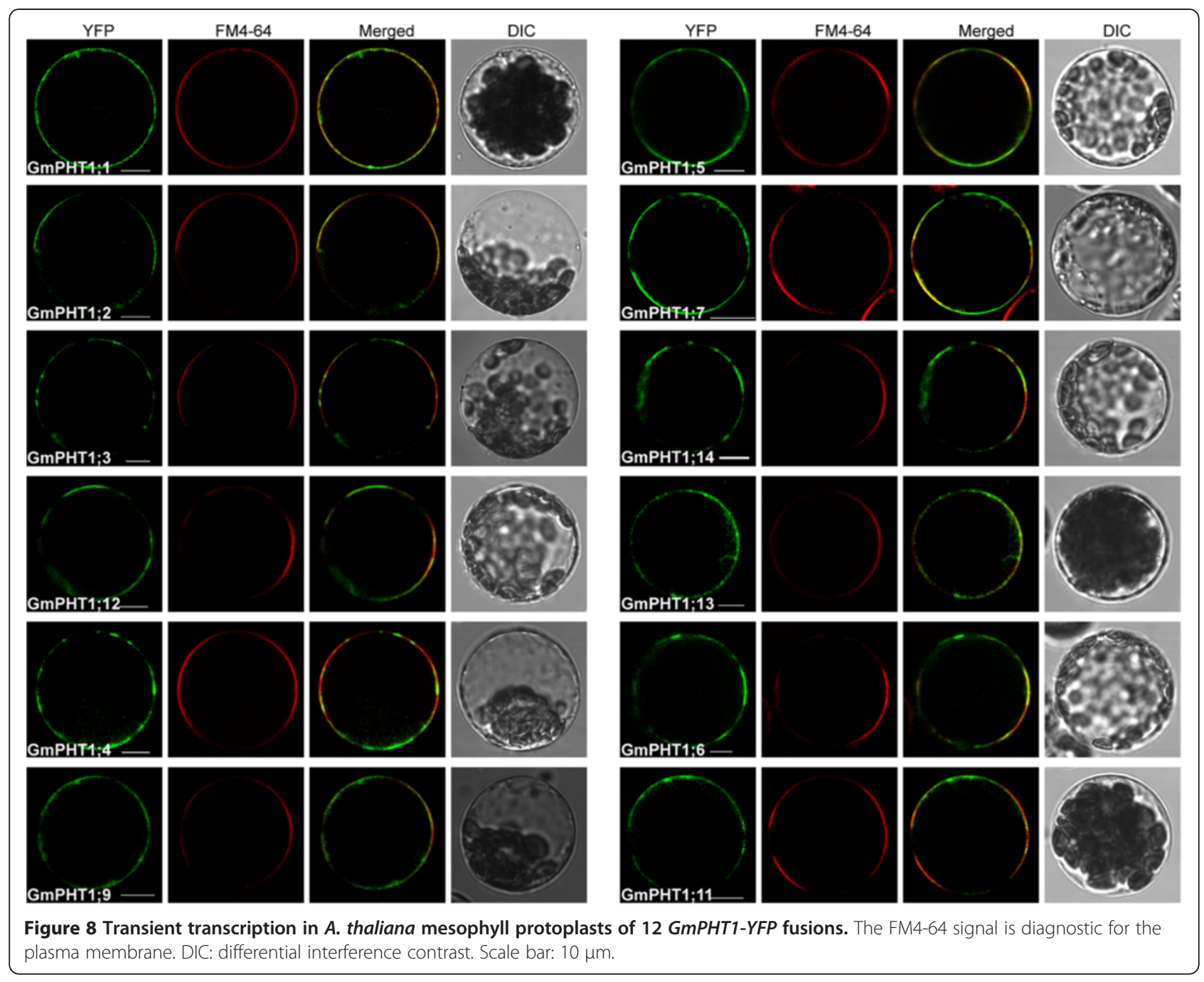

the contrary, subfunctionalization would be expected to undergo purifying selection. The $\mathrm{Ka} / \mathrm{Ks}$ values for all soybean PHT1 genes were less than 1.0 (Additional file 5F), thus, the paralog PHT1 gene pairs were undergoing purifying selections in the soybean evolution and subfunctionalized. In the soybean genome, about $75 \%$ genes are present in multiple copies, and approximately 50\% of paralogs are differentially expressed and have undergone expression subfunctionalization, and only a small proportion of the duplicated genes have been neofunctionalized or non-functionalized [12], suggesting that the main fate of duplicated genes were subfunctionalization.

Although the different functions of Pi transport were that they have different affinities, all the published PHT1 genes display conserved functions of Pi transport. In one species, the greatest difference is the divergence of their expression profile, which results in their differently functional sites in the plant. In Arabidospsis, AtPHT1;6 expresses only in flowers, and both AtPHT1;8 and 9 express only in the roots [52], and transcriptions of AtPHT1;5 are detected in the old tissues and induced by ethylene [59]. Additionally, most AtPHT1 genes exhibit strong expression in several tissues although their expressions overlapped to some extent [16]. In angiosperms, some members of the PHT1 family, such as MtPT4, OsPT11, OsPT13, TaPHT1, HvPT8, StPT4, LePT4 and PtPT10, are induced only by AMF, while transcriptions of other members, such as StPT3, OsPT1, OsPT2, OsPT3, OsPT6, OsPT9, and OsPT10 are not special to AMF [30,57,60-64]. The response of most PHT1 genes to the low Pi are similar, but to deficiencies of other nutrient elements, such as nitrogen, potassium, iron, and zinc, are different $[27,65]$. Three different paralog gene pairs, show different expression patterns or levels under deficient $\mathrm{N}, \mathrm{K}$, or Fe conditions [27], suggesting another subfunctionalization event among these paralogs.

Subfunctionalization can be taken as genetic redundancy [66,67]. For example, in Arabidopsis, the Pi uptake rates of single mutants, pht1;1 and pht1;4, were reduced about 20\%, but the rate of double mutant was reduced approximately 

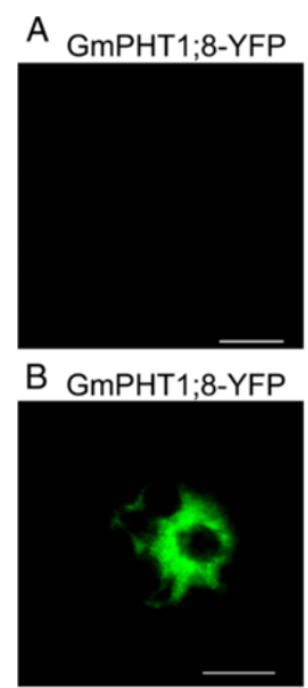

C GmPHT1;10-YFP

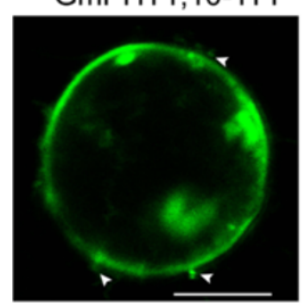

D GmPHT1;10-YFP

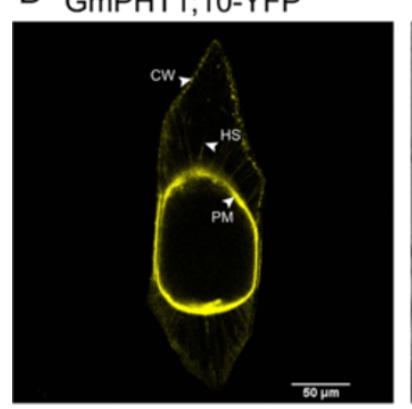

FM4-64

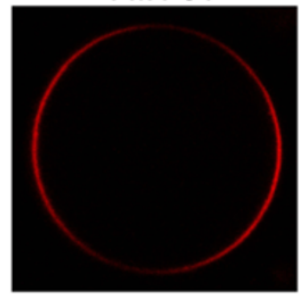

ER-mRFP

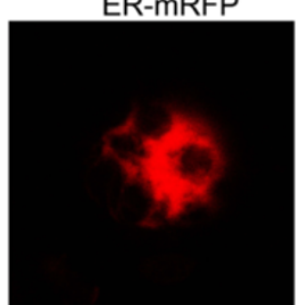

FM4-64
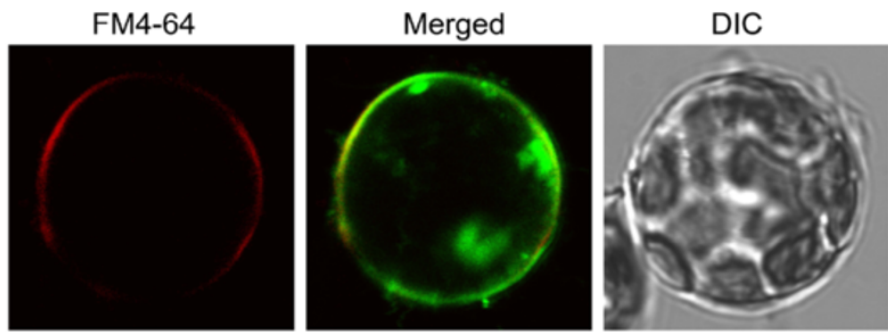

DIC
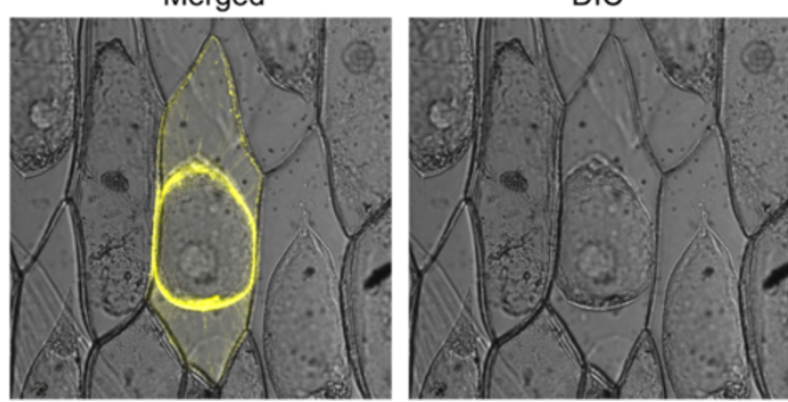

Figure 9 Sub-cellular localization of GmPHT1;8 and GmPHT1;10 in A. thaliana protoplasts. A, No signal of GmPHT1;8-YFP on plasma membrane. FM4-64: plasma membrane marker. B, The co-localization of GmPHT1;8-YFP with the ER specific marker mRFP. C, The subcellular localization of GmPHT1;10-YFPAnd FM4-64: plasma membrane marker. Arrow heads display extracellular signals. D, The localization of GmPHT1;10 in plasmolyzed onion epidermal cells. CW: cell wall, HS: Hechtian strands, PM: plasma membrane. Scale bar: $10 \mu \mathrm{m}$ for A, B, and C, $50 \mu \mathrm{m}$ for D.

$57 \%$, under the low-Pi condition [37]. Mutations in tomato (Solanum lycopersicum) StPT4 affected neither mycorrhizal Pi uptake nor establishment of the symbiotic pathway, this was due to arbuscular-mycorrhizal symbiosis triggering expression of other three PHT1 genes [64]. These results indicate $\mathrm{Pi}$ uptake functionally redundancy. The expression profiles of soybean PHT1 (Figure 2), indicates extensively overlaid, these results suggest redundancy in these paralogs as well.

PHT1, as a plasma membrane protein, consists of two regions of six transmembrane domains separated by a hydrophilic loop [68,69]. All the 14 soybean PHT1 proteins, like other PHT1s, contain 12 transmembrane domains (Additional file 8). Up to now, the PHT1 family members were believed to localize finally to the plasma membrane (the function site) after post-translational modifications $[38,70]$. According to our results (Figure 8), the fluorescence signals of most soybean PHT1s were detected in the plasma membrane. Except the plasma membrane, the fluorescence signals of MtPT3 [20] and AtPHT1;1 [37] can be detected in hechtian strands. The subcellular localization of GmPHT1;10 in onion epidermal cells was similar to that of MtPT3 and AtPHT1;1 (Figure 9D), but the same localization pattern was not observed in its paralog 
(Additional file 9). Interestingly, the localization of $\mathrm{Gm}$ PHT1;8 was not at the cytoplasmic membrane but at the endoplasmic reticulum (Figure 9B), however its paralog, GmPHT1;9, localized to the plasma membrane.

\section{Subfunctionalization of paralogs beneficial to soybean $\mathrm{Pi}$ uptake, translocation and remobilization}

To enhance acquisition of external Pi, plants can morphologically regulate root architecture to enhance the root surface/soil volume ratio, also root architecture is closely related to $\mathrm{P}$ efficiency [40,71-74]. The number and length of lateral roots and the length of primary roots increased under the low-Pi condition (Additional file 9). At the molecular level, the members of PHT1 family play important roles in Pi uptake from soil solutions thus exhibiting robust expression in roots $[16,40]$. According to our results (Figure 4) and others' [27], fourteen soybean PHT1 genes expressed in the root were up-regulated by low-Pi stress. Moreover, GmPHT1;1, 2, 5, 7, and 10 had high affinity to Pi. Thus, GmPHT1;1, 2, 5,7 , and 10 may play important roles in the direct Pi uptake from low-Pi soil solutions.

In addition to direct $\mathrm{Pi}$ uptake, symbiotic phosphate uptake is an ancestral $\mathrm{Pi}$ acquisition strategy for plants, meaning that some PHT1 genes are induced by arbuscular mycorrhizas $[16,29,40,63,75]$. In the soybean, the transcription of three soybean PHT1 genes, GmPT7, 10 and 11 (GmPHT1;11, 13, and 12, respectively in this study), was induced by arbuscular mycorrhizal fungi [26]. These results indicate these three genes have important roles in soybean symbiotic Pi uptake.

After Pi uptake, distribution and remobilization of $\mathrm{Pi}$, within the plant, is accomplished through the membrane transport systems of the shoots to the sink tissues wherever symplastic connections are lost [15,40]. Although other PHT gene families, such as the PHT2 family [76], are involved the process, the PHT1 gene family localization in the plasma membrane is the most important $[19,52,77,78]$. Based on our results, GmPHT1;7, 8, 10 and 12 exhibited stronger expression than their corresponding paralog genes in the stems, at the seedling and flowering stage (Figure 2), suggesting involvement in internal Pi transport in the shoots.

Another developmental signal, senescence, has been reported to strongly induced expression of some PHT1 genes $[30,59,79]$, and most leaf phosphorus is remobilized to the seed during reproductive development in soybean [80]. For instance, in other plants, the expression of PhPT1 is up regulated during petunia petal senescence [79] and transcript level of Pht1;5 is elevated in the old leaves in Arabidopsis [59]. In the soybean, GmPHT1;1 expression increased in unifoliolates along with developmental process and reached the peak during flowering time (Figure 2). Moreover, again during flowering time, the transcription level of $G m P H T 1 ; 1$ was relative to leaf ages (Figure 2). This suggests that GmPHT1;1 is related to the re-utilization of $\mathrm{Pi}$ from older leaves. Cotyledons are the main phosphorus store tissue and the phosphorus resource tissue at the seedling stage. High expression of GmPHT1;8 was detected in the cotyledons at the seedling stage (Figure 2), suggesting GmPHT1;8 played an important roles in recycling $\mathrm{Pi}$ from cotyledons.

Different subcellular localizations of GmPHT1 proteins correlated to cellular homeostasis according to our findings. Although the majority of GmPHT1 proteins localized on cytoplasma membrane (Figure 8), similarly to PHT1s in other plants [81], GmPHT1;8 and GmPHT1;10 have unique localization patterns. GmPHT1;10 localized to Hechtian strands in addition to the cytoplasma membrane and cell walls. These Hechtian transporters may play critical roles in Pi transport between the cytoplasmic membrane and cell wall or between cells [82]. Perhaps, GmPHT1;10 had important roles in the cross talk of Pi flux or signals amongst the cells. In addition, GmPHT1;8 localized, exclusively, to the endomembrane system instead of cytoplasma membrane (Figure 9B). A functional auxin transporter, AtPIN5, does not have a direct role in cell-to-cell transport but regulates intracellular auxin homeostasis and localizes to endoplasmic reticulum (ER), unlike other characterized plasma membrane PIN proteins [83]. Given the function of the AtPIN5, this result may indicate GmPHT1;8 has a role in regulating intracellular Pi homeostasis and metabolism.

\section{Conclusion}

In the soybean, there were 14 PHT1 genes with full whole CDS plus one pseudogene, and they originated from four different different ancestors, GmPHT1A, B, C and D, before the Gamma WGT events in the soybean evolution history. Three polyploidy events expanded the members of GmPHT1A. In addition, one tandem duplication also increased the members of GmPHT1A after the Legume WGD and before the Glycine WGD. The retentions of paralog genes of GmPHT1B and C were only after the Glycine WGD. GmPHT1D contained one member, of which paralog gene was lost. Fourteen soybean PHT1s underwent the purifying selection and had the conserved function in $\mathrm{Pi}$ uptake although they had different affinities for $\mathrm{Pi}$, and GmPHT1;15 experienced pseudogenization. Expression divergence levels were the main style of subfunctionalization of the paralog gene pairs. The expression ratios were more than two amongst paralog gene pairs in about $76 \%$ co-expression tissues. Although 14 soybean PHT1 genes more strongly expressed in the roots under the low Pi condition, the response extent were different. Similar subcelluar localizations to the plasma membrane were found amongst most soybean PHT1 proteins. But GmPHT1;8 was not localized to the 
plasma membrane but to the endoplasmic reticulum, while GmPHT1;10 was localized to Hechtian strands in addition to plasma membranes.

\section{Methods \\ Plant materials}

We employed the soybean cultivar (KN18) in all experiments. Plants were grown in a growth chamber under short day conditions ( $8 \mathrm{hr}$ light/16 hr dark) at a temperature $25^{\circ} \mathrm{C} \sim 28^{\circ} \mathrm{C}$. Tissues harvested at two different developmental stages, fully expanded unifoliolate leaf and flowering onset, were evaluated for GmPHT1 expression patterns and levels in different tissues. We collected pods samples 7, 14 and 21days after flowering. To investigate the effect of external $\mathrm{Pi}$ concentrations of GmPHT1 transcription, plants raised in a hydroponic culture with an initial Pi concentration of $500 \mu \mathrm{M}$. Once unifoliolate leaves were fully expanded, the culture solution Pi concentration was changed to $1 \mu \mathrm{M}, 10 \mu \mathrm{M}$, $100 \mu \mathrm{M}, 500 \mu \mathrm{M}, 1 \mathrm{mM}, 2 \mathrm{mM}$ or $5 \mathrm{mM}$. Solutions were refreshed once every two days over the course of one week. Each experimental group, containing a minimum of five individual plants per group, was harvested, frozen in liquid nitrogen and stored at $-80^{\circ} \mathrm{C}$ until required. All experiments were repeated three times under the consistent conditions.

\section{Identification, cloning and expression vector construction of soybean PHT1 genes}

Soybean genome sequences (version 1.09), downloaded from Phytozome V 8.0, and used to obtain a set of known PHT1 sequences (Additional file 1). Members of the GmPHT1 family (Additional file 5F) were identified using profile hidden Markov models built by HMMER v3.0 [84], following the HMMER user guide. The GMPHT1 gene nomenclature is presented in Additional file 5F. A pseudogene $(G m P H T 1 ; 15)$ was predicted from syntenic analysis using the PGDD or CoGe database.

Given the sequence similarity between the 14 PHT1 genes in this study, we designed primers specific to the $5^{\prime}$ or $3^{\prime}$ UTR of each gene (Additional file 5F) for RT-PCR. Subsequently, these sequences were used as templates to clone the CDSs with corresponding primers (Additional file $5 \mathrm{E}$ ) into an entry vector pGWC [85], next genes were recombined into an appropriate yeast expression vector, pYES-DEST52 (Invitrogen), and plant expression vectors, pEXSG-YFP-GW, with Gateway technology.

\section{Bioinformatic analysis}

To identify the intra-genome (G. $\max$ ) or cross-genome (G. $\max$ and $M$. truncatula) syntenic relationships we employed, SynMap (http://genomevolution.org/CoGe/Syn Map.pl). To investigate the synteny of blocks containing PHT1 genes, homology data derived from CDS-CDS comparisons made using Blastz, with an E-value cutoff of $1 \mathrm{e}-5$, other parameters were default or recommended. The nine members of the PHT1 gene family was identified (Additional file 5B) in M. truncatula as above.

Transmembrane (TM) domains of PHT genes were predicted by TopPred 2 (http://bioweb.pasteur.fr/seqanal/ interfaces/toppred.html) [86]. PLACE [31] (http://www. dna.affrc.go.jp/PLACE/signalscan.html) was employed to scan the cis-acting elements of the predicted promoter sequences for every GmPHT1 genes. After alignment of the full GmPHT1 genes' CDS by ClustalW (http://www.ebi.ac. uk/Tools/msa/clustalw2/), Ka (non-synonymous substitutions per non-synonymous site) and Ks (synonymous substitutions per synonymous site) of the paralog genes was computed by DnaSP v5 (Additional file 5F) [87].

\section{Yeast manipulations}

The yeast Pi uptake-defective mutant PAM2 ( $\Delta$ pho84 $\Delta$ pho89) [36] was employed to identify the Pi transport activities of the 14 GmPHT1 genes. All GmPHT1 yeast recombinant expression vectors carrying PHT1 CDS were transformed into PAM2. Transformed cells grew to logarithmic phase in a synthetic liquid medium (SM, 1 liter: $5.9 \mathrm{~g}$ YNB (CYN0804, For Medium), $0.77 \mathrm{~g}$ mixture of amino acid without Ura (Clontech), 2\% raffinose, $6 \mathrm{mM} \mathrm{Pi}$, $\mathrm{pH} 5.8$ ). The cells were harvested when enter the log phase, washed with Pi-free medium, and re-suspended in the same medium to different concentration. For yeast mutant complementation experiments, the yeast cells dilution were plated onto solid, induced or non-induced, medium (1 liter: $5.9 \mathrm{~g}$ YNB, $0.77 \mathrm{~g}$ mixture of amino acid without Ura, $2 \%$ galactose or glucose, $2 \%$ agar (\#05038, sigma), $10 \mu \mathrm{M} \mathrm{Pi}$, $\mathrm{pH}$ 6.5). Potassium was supplemented with equivalent $\mathrm{KCl}$, and $0.04 \%$ bromocresol purple was used as a $\mathrm{pH}$ indicator [19], plates were incubated at $30^{\circ} \mathrm{C}$, for 3 days. We performed $\mathrm{Pi}$ uptake experiments using ${ }^{32} \mathrm{Pi}$ as previously reported [20]. Yeast cells grew in liquid, non-induced medium (1 mM Pi) for $6 \mathrm{hr}$, cells were harvested, and then washed with the Pi-free medium 3 times. Next, yeast cells were grown in liquid, induced medium, without $\mathrm{Pi}$, for 4 hours, harvested and washed with water 3 times. After the final wash, cells were resuspended at $200 \mathrm{mg}$ cells $/ \mathrm{ml}^{-1}$. Cell suspension $30 \mu \mathrm{L}$ was added to YNB medium $(570 \mu \mathrm{l})$, containing $25 \mathrm{mM}$ sodium citrate (pH4.5), 2\% glucose and appropriate concentration gradient of $\mathrm{Pi}(10 \mu \mathrm{M}, 50 \mu \mathrm{M}$, $100 \mu \mathrm{M}, 300 \mu \mathrm{M}, 500 \mu \mathrm{M}$ or $1000 \mu \mathrm{M})$. Radioactive ${ }^{32} \mathrm{Pi}$ was added to the yeast solution at a final concentration of $0.125 \mu \mathrm{Ci}$, and cells were incubated at $30^{\circ} \mathrm{C}$ with gentle agitation for $3 \mathrm{~min}$. Immediately, we added $4 \mathrm{ml}$ of ice-cold stop solution ( $25 \mathrm{mM}$ sodium citrate buffer, $\mathrm{pH} 4.5$ ) transferred onto glass fiber filters and washed with an additional $4 \mathrm{ml}$ of stop solution. A scintillation spectroscopy measured the samples radioactivity. All experiments were repeated three times with similar results. The kinetic data was 
analyzed by nonlinear regression with GraphPad Prism 5 software.

\section{Total RNA isolation and quantitative reverse transcription-PCR (RT-qPCR)}

The procedures used for RNA extraction and cDNA synthesis are as described by $\mathrm{Hu}$, et al [88]. All expression experiments were repeated a minimum of three times. The primers for the 15 PHT1 genes examined by qRT-PCR are listed in Additional file 5F and 14 of the primer pairs had an efficiency greater than $90 \%$ as determined by LinReg PCR (http://LinRegPCR.HFRC.nl) [89]. GmSKIP16, and GmUNK1 were used as reference genes for all qRT-PCRs [88]. The relative expression was computed following the formula $2^{\text {(Cta-Ctb) }}$, where $C_{t} a$ and $C_{t} b$ are the average $C_{t}$ values of the reference and target genes, respectively.

\section{Subcellular localization analysis}

Transient expression of YFP tagged GmPHT1 were performed in Arabidopsis mesophyll protoplasts through PEG-calcium transfection [90] and in onion epidermal cells by bombardment [20]. Experiments were carried out to analyze subcellular localizations of $14 \mathrm{GmPHT}$ proteins and to investigate the cellular localization of GmPHT1 proteins in vivo. Specific subcellular organelles markers, plasma membrane (FM4-64) [91] and endoplasmic reticulum (ER-mRFP) [39], were selected. Section Z-series images were collected at different intervals throughout the specimens to facilitate observation. Twenty to thirty cells were imaged for each experiment. Post-acquisition image analysis and processing was performed using MBF ImageJ, version 1.46

\section{Additional files}

Additional file 1: A list of known plant PHT1 genes.

Additional file 2: The nomenclature of soybean PHT1s in different papers.

Additional file 3: GmPHT1 promoters, genes and gene structures. Additional file 4: $\mathrm{PHT} 1$ phylogenetic tree.

Additional file 5: A, The cis-acting regulatory DNA elements present within the $14 \mathrm{GmPHT1}$ promoters. B, The PHT1 gene family in M.truncatula and synteny blocks harbouring PHT1s among soybean and Medicago. C, Synteny between GmPHT1 containing segments in soybean D, Relative transcript abundance of the various GMPHT1 genes across different tissues. E, The information of the set of GMPHT1 genes and the primer sequences used for RT-GPCR and gene cloning experiments. F, The Ks and Ka values among GMPHT1 genes.

Additional file 6: The growth of the yeast double mutant PAM2 in the presence of various concentrations of $\mathrm{Pi}$.

Additional file 7: Transient transcription of the GMPHT1;1-YFP, GmPHT1;5-YFP and GmPHT1;6-YFP fusions in plasmolyzed onion epidermal cells.

Additional file 8: Motifs and domains shared by the GmPHT1 and other PHT1 proteins.
Additional file 9: The appearance of soybean roots in plants subjected to different Pi concentration conditions.

Competing interests

The authors declare that they have no competing interests.

\section{Authors' contributions}

CF carried out all the analysis and interpreted the results, and wrote the manuscript. XW and RH participated in the data mining. YW and CX carried out RT-qPCR. YJ and XZ helped in soybean materials collection and total RNA extraction. YF and CZ conceived the project, supervised the analysis and critically revised the manuscript. All authors read and approved the final manuscript.

\section{Acknowledgments}

This work was partly supported by Transgenic program (2009ZX08009-133B), the Chinese National Key Basic Research Program "973" (2010CB125906), National High Technology Research and Development Program "863" (2013AA102602) and the National Natural Science Founds (31000680). Thank to Bengt L. Persson for yeast mutant PAM2, George Coupland for vectors of pEXSG-CFP-GW and pEXSG-YFP-GW, Long Mao for bioinformatics support, and Robert Koebner for language editing.

\section{Author details}

'MOA Key Lab of Soybean Biology (Beijing), National K'ey Facility of Crop Gene Resource and Genetic Improvement, Institute of Crop Sciences, Chinese Academy of Agricultural Sciences, 12 Zhongguancun Nandajie, Haidian District, Beijing 100081, China. ${ }^{2}$ CAS Key Laboratory of Biofuels, Shandong Provincial Key Laboratory of Energy Genetics, Qingdao Institute of BioEnergy and BioProcess Technology, Chinese Academy of Sciences, Qingdao, Shandong 266101, China. ${ }^{3}$ College of Agronomy and Plant Protection, Qingdao Agricultural University, Qingdao 266109, China.

Received: 24 January 2013 Accepted: 14 March 2013

Published: 20 March 2013

\section{References}

1. Edger PP, Pires JC: Gene and genome duplications: the impact of dosage-sensitivity on the fate of nuclear genes. Chromosome Res 2009, 17(5):699-717.

2. Wang Y, Wang X, Paterson AH: Genome and gene duplications and gene expression divergence: a view from plants. Ann N Y Acad Sci 2012, 1256:1-14.

3. Buggs RJ, Elliott NM, Zhang L, Koh J, Viccini LF, Soltis DE, Soltis PS: Tissuespecific silencing of homoeologs in natural populations of the recent allopolyploid Tragopogon mirus. New Phytol 2010, 186(1):175-183.

4. Conant GC, Wolfe KH: Turning a hobby into a job: how duplicated genes find new functions. Nat Rev Genet 2008, 9(12):938-950

5. Freeling M: Bias in plant gene content following different sorts of duplication: tandem, whole-genome, segmental, or by transposition. Annu Rev Plant Biol 2009, 60:433-453.

6. Cusack BP, Wolfe KH: When gene marriages don't work out: divorce by subfunctionalization. Trends in genetics: TIG 2007, 23(6):270-272.

7. Blanc $\mathrm{G}$, Wolfe KH: Functional divergence of duplicated genes formed by polyploidy during Arabidopsis evolution. Plant Cell 2004, 16(7):1679-1691.

8. Moore RC, Purugganan MD: The evolutionary dynamics of plant duplicate genes. Curr Opin Plant Biol 2005, 8(2):122-128.

9. Schnable JC, Springer NM, Freeling M: Differentiation of the maize subgenomes by genome dominance and both ancient and ongoing gene loss. Proc Natl Acad Sci USA 2011, 108(10):4069-4074.

10. Thomas BC, Pedersen B, Freeling M: Following tetraploidy in an Arabidopsis ancestor, genes were removed preferentially from one homeolog leaving clusters enriched in dose-sensitive genes. Genome Res 2006, 16(7):934-946

11. Woodhouse MR, Schnable JC, Pedersen BS, Lyons E, Lisch D, Subramaniam $S$, Freeling M: Following tetraploidy in maize, a short deletion mechanism removed genes preferentially from one of the two homologs. PLOS Biol 2010, 8(6):e1000409. 
12. Roulin A, Auer PL, Libault M, Schlueter J, Farmer A, May G, Stacey G, Doerge RW, Jackson SA: The fate of duplicated genes in a polyploid plant genome. The Plant journal: for cell and molecular biology 2012, 73(1):143-153.

13. Fernandez A, Tzeng YH, Hsu SB: Subfunctionalization reduces the fitness cost of gene duplication in humans by buffering dosage imbalances. BMC Genomics 2011, 12:604.

14. Nussaume L, Kanno S, Javot H, Marin E, Pochon N, Ayadi A, Nakanishi TM, Thibaud MC: Phosphate Import in Plants: Focus on the PHT1 Transporters. Front Plant Sci 2011, 2:83.

15. Schachtman DP, Reid RJ, Ayling SM: Phosphorus uptake by plants: from soil to cell. Plant Physiol 1998, 116(2):447-453.

16. Nussaume L, Kanno S, Javot H, Marin E, Nakanishi TM, Thibaud M-C: Phosphate import in plants: focus on the PHT1 transporters. Frontiers in Plant Science 2011, 2:83.

17. Bucher M: Functional biology of plant phosphate uptake at root and mycorrhiza interfaces. New Phytol 2007, 173(1):11-26.

18. Lambers H, Raven JA, Shaver GR, Smith SE: Plant nutrient-acquisition strategies change with soil age. Trends Ecol Evol 2008, 23(2):95-103.

19. Ai P, Sun S, Zhao J, Fan X, Xin W, Guo Q, Yu L, Shen Q, Wu P, Miller AJ, et al: Two rice phosphate transporters, OsPht $1 ; 2$ and OsPht $1 ; 6$, have different functions and kinetic properties in uptake and translocation. Plant $J$ 2009, 57(5):798-809.

20. Liu J, Versaw WK, Pumplin N, Gomez SK, Blaylock LA, Harrison MJ: Closely related members of the Medicago truncatula PHT1 phosphate transporter gene family encode phosphate transporters with distinct biochemical activities. J Biol Chem 2008, 283(36):24673-24681.

21. Lu Q, Zhao J, Tian J, Chen L, Sun Z, Guo Y, Lu X, Gu M, Xu G, Liao H: The high-affinity phosphate transporter GmPT5 regulates phosphate transport to nodules and nodulation in soybean. Plant Physiol 2012, 159(4):1634-1643.

22. Rae AL, Cybinski DH, Jarmey JM, Smith FW: Characterization of two phosphate transporters from barley; evidence for diverse function and kinetic properties among members of the Pht 1 family. Plant Mol Biol 2003, 53(1-2):27-36.

23. Schmutz J, Cannon SB, Schlueter J, Ma J, Mitros T, Nelson W, Hyten DL, Song Q, Thelen JJ, Cheng J, et al: Genome sequence of the palaeopolyploid soybean. Nature 2010, 463(7278):178-183.

24. Schlueter JA, Lin JY, Schlueter SD, Vasylenko-Sanders IF, Deshpande S, Yi J, O'Bleness M, Roe BA, Nelson RT, Scheffler BE, et al: Gene duplication and paleopolyploidy in soybean and the implications for whole genome sequencing. BMC Genomics 2007, 8:330

25. Severin AJ, Cannon SB, Graham MM, Grant D, Shoemaker RC: Changes in twelve homoeologous genomic regions in soybean following three rounds of polyploidy. Plant Cell 2011, 23(9):3129-3136.

26. Tamura $Y$, Kobae $Y$, Mizuno T, Hata S: Identification and expression analysis of arbuscular mycorrhiza-inducible phosphate transporter genes of soybean. Biosci Biotechnol Biochem 2012, 76(2):309-313.

27. Qin L, Guo Y, Chen L, Liang R, Gu M, Xu G, Zhao J, Walk T, Liao H: Functional characterization of 14 pht 1 family genes in yeast and their expressions in response to nutrient starvation in soybean. PLoS One 2012, 7(10):e47726.

28. Wu Z, Zhao J, Gao R, Hu G, Gai J, Xu G, Xing H: Molecular cloning, characterization and expression analysis of Two members of the Pht1 family of phosphate transporters in Glycine max. PLoS One 2011, 6(6):e19752

29. Karandashov $V$, Bucher M: Symbiotic phosphate transport in arbuscular mycorrhizas. Trends Plant Sci 2005, 10(1):22-29.

30. Loth-Pereda V, Orsini E, Courty PE, Lota F, Kohler A, Diss L, Blaudez D, Chalot $M$, Nehls $U$, Bucher $M$, et al: Structure and expression profile of the phosphate Pht1 transporter gene family in mycorrhizal Populus trichocarpa. Plant Physiol 2011, 156(4):2141-2154.

31. Higo $K$, Ugawa $Y$, Iwamoto $M$, Korenaga T: Plant cis-acting regulatory DNA elements (PLACE) database: 1999. Nucleic Acids Res 1999, 27(1):297-300

32. Beilstein MA, Nagalingum NS, Clements MD, Manchester SR, Mathews S: Dated molecular phylogenies indicate a miocene origin for arabidopsis thaliana. Proc Natl Acad Sci USA 2010, 107(43):18724-18728.

33. Young ND, Debelle F, Oldroyd GED, Geurts R, Cannon SB, Udvardi MK, Benedito VA, Mayer KFX, Gouzy J, Schoof H, et al: The Medicago genome provides insight into the evolution of rhizobial symbioses. Nature 2011, 480(7378):520-524
34. Subramanian S, Kumar S: Gene expression intensity shapes evolutionary rates of the proteins encoded by the vertebrate genome. Genetics 2004, 168(1):373-381.

35. Abel S: Phosphate sensing in root development. Curr Opin Plant Biol 2011, 14(3):303-309.

36. Martinez P, Persson BL: Identification, cloning and characterization of a derepressible $\mathrm{Na}^{+}$-coupled phosphate transporter in Saccharomyces cerevisiae. Mol Gen Genet 1998, 258(6):628-638.

37. Shin H, Shin HS, Dewbre GR, Harrison MJ: Phosphate transport in Arabidopsis: Pht 1;1 and Pht1;4 play a major role in phosphate acquisition from both low- and high-phosphate environments. Plant $J$ 2004, 39(4):629-642.

38. Bayle V, Arrighi J-F, Creff A, Nespoulous C, Vialaret J, Rossignol M, Gonzalez E, Paz-Ares J, Nussaume L: Arabidopsis thaliana high-affinity phosphate transporters exhibit multiple levels of posttranslational regulation. Plant Cell 2011, 23(4):1523-1535.

39. Nelson BK, Cai $X$, Nebenfuhr A: A multicolored set of in vivo organelle markers for co-localization studies in Arabidopsis and other plants. Plant J 2007, 51(6):1126-1136.

40. Smith FW, Mudge SR, Rae AL, Glassop D: Phosphate transport in plants. Plant Soil 2003, 248(1):71-83.

41. Raghothama KG: Phosphate transport and signaling. Curr Opin Plant Biol 2000, 3(3):182-187

42. Miura K, Lee J, Gong Q, Ma S, Jin JB, Yoo CY, Miura T, Sato A, Bohnert HJ, Hasegawa PM: SIZ1 regulation of phosphate starvation-induced root architecture remodeling involves the control of auxin accumulation. Plant Physiol 2011, 155(2):1000-1012.

43. Svistoonoff S, Creff A, Reymond M, Sigoillot-Claude C, Ricaud L, Blanchet A, Nussaume L, Desnos T: Root tip contact with lowphosphate media reprograms plant root architecture. Nat Genet 2007, 39(6):792-796.

44. Lopez-Bucio J, Cruz-Ramirez A, Herrera-Estrella L: The role of nutrient availability in regulating root architecture. Curr Opin Plant Biol 2003, 6(3):280-287.

45. Karandashov V, Nagy R, Wegmuller S, Amrhein N, Bucher M: Evolutionary conservation of a phosphate transporter in the arbuscular mycorrhizal symbiosis. Proc Natl Acad Sci USA 2004, 101(16):6285-6290.

46. Wellman $\mathrm{CH}$, Osterloff $\mathrm{PL}$, Mohiuddin U: Fragments of the earliest land plants. Nature 2003, 425(6955):282-285.

47. Redecker D, Kodner R, Graham LE: Glomalean fungi from the Ordovician. Science 2000, 289(5486):1920-1921.

48. Bonfante $P$, Genre A: Mechanisms underlying beneficial plant-fungus interactions in mycorrhizal symbiosis. Nat Commun 2010, 1:48.

49. Adams KL, Wendel JF: Polyploidy and genome evolution in plants. Curr Opin Plant Biol 2005, 8(2):135-141.

50. Tang H, Bowers JE, Wang X, Ming R, Alam M, Paterson AH: Synteny and collinearity in plant genomes. Science 2008, 320(5875):486-488.

51. Blanc $G$, Hokamp K, Wolfe KH: A recent polyploidy superimposed on older large-scale duplications in the Arabidopsis genome. Genome Res 2003, 13(2):137-144

52. Mudge SR, Rae AL, Diatloff E, Smith FW: Expression analysis suggests novel roles for members of the Pht1 family of phosphate transporters in Arabidopsis. Plant J 2002, 31(3):341-353.

53. Okumura S, Mitsukawa N, Shirano Y, Shibata D: Phosphate transporter gene family of Arabidopsis thaliana. DNA Res 1998, 5(5):261-269.

54. Tuskan GA, Difazio S, Jansson S, Bohlmann J, Grigoriev I, Hellsten U, Putnam N, Ralph S, Rombauts S, Salamov A, et al: The genome of black cottonwood, Populus trichocarpa (Torr. \& Gray). Science 2006, 313(5793):1596-1604.

55. Guyot R, Keller B: Ancestral genome duplication in rice. Genome / National Research Council Canada $=$ Genome / Conseil national de recherches Canada 2004, 47(3):610-614.

56. Yang SY, Gronlund M, Jakobsen I, Grotemeyer MS, Rentsch D, Miyao A Hirochika H, Kumar CS, Sundaresan V, Salamin N, et al: Nonredundant Regulation of Rice Arbuscular Mycorrhizal Symbiosis by Two Members of the PHOSPHATE TRANSPORTER1 Gene Family. Plant Cell 2012, 24(10):4236-4251.

57. Paszkowski U, Kroken S, Roux C, Briggs SP: Rice phosphate transporters include an evolutionarily divergent gene specifically activated in arbuscular mycorrhizal symbiosis. Proc Natl Acad Sci USA 2002, 99(20):13324-13329. 
58. Hurles M: Gene duplication: the genomic trade in spare parts. PLOS Biol 2004, 2(7):E206.

59. Nagarajan VK, Jain A, Poling MD, Lewis AJ, Raghothama KG, Smith AP: Arabidopsis Pht1;5 Mobilizes Phosphate between Source and Sink Organs and Influences the Interaction between Phosphate Homeostasis and Ethylene Signaling. Plant Physio/ 2011, 156(3):1149-1163.

60. Pumplin N, Zhang $X$, Noar RD, Harrison MJ: Polar localization of a symbiosis-specific phosphate transporter is mediated by a transient reorientation of secretion. Proc Natl Acad Sci 2012, 109(11):E665-E672.

61. Harrison MJ, Dewbre GR, Liu J: A phosphate transporter from Medicago truncatula involved in the acquisition of phosphate released by arbuscular mycorrhizal fungi. Plant Cell 2002, 14(10):2413-2429.

62. Kobae $Y$, Hata S: Dynamics of periarbuscular membranes visualized with a fluorescent phosphate transporter in arbuscular mycorrhizal roots of rice. Plant Cell Physiol 2010, 51(3):341-353.

63. Javot H, Pumplin N, Harrison MJ: Phosphate in the arbuscular mycorrhizal symbiosis: transport properties and regulatory roles. Plant Cell Environ 2007, 30(3):310-322.

64. Nagy R, Karandashov V, Chaque V, Kalinkevich K, Tamasloukht M, Xu G, Jakobsen I, Levy AA, Amrhein N, Bucher M: The characterization of novel mycorrhiza-specific phosphate transporters from Lycopersicon esculentum and Solanum tuberosum uncovers functional redundancy in symbiotic phosphate transport in solanaceous species. Plant J 2005, 42(2):236-250.

65. Huang C, Barker SJ, Langridge P, Smith FW, Graham RD: Zinc deficiency upregulates expression of high-affinity phosphate transporter genes in both phosphate-sufficient and -deficient barley roots. Plant Physio/ 2000, 124(1):415-422.

66. DeLuna A, Vetsigian K, Shoresh N, Hegreness M, Colon-Gonzalez M, Chao S, Kishony R: Exposing the fitness contribution of duplicated genes. Nat Genet 2008, 40(5):676-681.

67. Gu Z, Steinmetz LM, Gu X, Scharfe C, Davis RW, Li WH: Role of duplicate genes in genetic robustness against null mutations. Nature 2003, 421(6918):63-66

68. Henderson PJ: The 12-transmembrane helix transporters. Curr Opin Cell Biol 1993, 5(4):708-721.

69. Petersson J, Pattison J, Kruckeberg AL, Berden JA, Persson BL: Intracellular localization of an active green fluorescent protein-tagged Pho84 phosphate permease in Saccharomyces cerevisiae. FEBS Lett 1999 462(1-2):37-42.

70. Lau W-TW, Howson RW, Malkus P, Schekman R, O'Shea EK: Pho86p, an endoplasmic reticulum (ER) resident protein in Saccharomyces cerevisiae, is required for ER exit of the high-affinity phosphate transporter Pho84p. Proc Natl Acad Sci 2000, 97(3):1107-1112.

71. Raghothama KG: Phosphate Acquisition. Annu Rev Plant Physiol Plant Mol Biol 1999, 50:665-693.

72. Zhao J, Fu J, Liao H, He Y, Nian H, Hu Y, Qiu L, Dong Y, Yan X: Characterization of root architecture in an applied core collection for phosphorus efficiency of soybean germplasm. Chinese Science Bulletin 2004, 49(15):1611-1620.

73. Williamson LC, Ribrioux SP, Fitter AH, Leyser HM: Phosphate availability regulates root system architecture in Arabidopsis. Plant Physiol 2001, 126(2):875-882.

74. Perez-Torres CA, Lopez-Bucio J, Cruz-Ramirez A, Ibarra-Laclette E, Dharmasiri S, Estelle M, Herrera-Estrella L: Phosphate availability alters lateral root development in Arabidopsis by modulating auxin sensitivity via a mechanism involving the TIR1 auxin receptor. Plant Cell 2008, 20(12):3258-3272.

75. Yang SY, Paszkowski U: Phosphate import at the arbuscule: just a nutrient? Mol Plant Microbe Interact 2011, 24(11):1296-1299.

76. Daram P, Brunner S, Rausch C, Steiner C, Amrhein N, Bucher M: Pht2; encodes a low-affinity phosphate transporter from Arabidopsis. Plant Cell 1999, 11(11):2153-2166.

77. Nagy R, Vasconcelos MJV, Zhao S, McElver J, Bruce W, Amrhein N, Raghothama KG, Bucher M: Differential Regulation of Five Pht1 Phosphate Transporters from Maize (Zea mays L.). Plant Biology 2006, 8(2):186-197.

78. Jia H, Ren H, Gu M, Zhao J, Sun S, Zhang X, Chen J, Wu P, Xu G: The Phosphate Transporter Gene OsPht1;8 Is Involved in Phosphate Homeostasis in Rice. Plant Physiol 2011, 156(3):1164-1175.

79. Chapin $\sqcup$, Jones ML: Ethylene regulates phosphorus remobilization and expression of a phosphate transporter (PhPT1) during petunia corolla senescence. J Exp Bot 2009, 60(7):2179-2190.
80. Lauer MJ, Blevins DG, Sierzputowska-Gracz H: ${ }^{31}$ P-nuclear magnetic resonance determination of phosphate compartmentation in leaves of reproductive soybeans (Glycine max L.) as affected by phosphate nutrition. Plant Physiol 1989, 89(4):1331.

81. Lin WY, Lin SI, Chiou TJ: Molecular regulators of phosphate homeostasis in plants. J Exp Bot 2009, 60(5):1427-1438.

82. Nick P: Signals, motors, morphogenesis-the cytoskeleton in plant development. Plant Biology 1999, 1:169-179.

83. Mravec J, Skupa P, Bailly A, Hoyerova K, Krecek P, Bielach A, Petrasek J, Zhang J, Gaykova V Stierhof YD, et al: Subcellular homeostasis of phytohormone auxin is mediated by the ER-localized PIN5 transporter. Nature 2009, 459(7250):1136-1140.

84. Finn RD, Clements J, Eddy SR: HMMER web server: interactive sequence similarity searching. Nucleic Acids Res 2011, 39(suppl 2):W29-W37.

85. Chen Q-J, Zhou H-M, Chen J, Wang X-C: Using a modified TA cloning method to create entry clones. Anal Biochem 2006, 358(1):120-125.

86. von Heijne G: Membrane protein structure prediction. Hydrophobicity analysis and the positive-inside rule. J Mol Biol 1992, 225(2):487-494.

87. Librado P, Rozas J: DnaSP v5: a software for comprehensive analysis of DNA polymorphism data. Bioinformatics 2009, 25(11):1451-1452.

88. Hu R, Fan C, Li H, Zhang Q, Fu Y-F: Evaluation of putative reference genes for gene expression normalization in soybean by quantitative real-time RT-PCR. BMC Mol Biol 2009, 10(1):93

89. Ruijter JM, Ramakers C, Hoogaars WM, Karlen Y, Bakker O, van den Hoff MJ, Moorman AF: Amplification efficiency: linking baseline and bias in the analysis of quantitative PCR data. Nucleic Acids Res 2009, 37(6):e45.

90. Yoo S-D, Cho Y-H, Sheen J: Arabidopsis mesophyll protoplasts: a versatile cell system for transient gene expression analysis. Nat Protocols 2007, 2(7):1565-1572.

91. Bolte S, Talbot C, Boutte Y, Catrice O, Read N, Satiat-Jeunemaitre B: FM-dyes as experimental probes for dissecting vesicle trafficking in living plant cells. J Microsc 2004, 214(2):159-173.

doi:10.1186/1471-2229-13-48

Cite this article as: Fan et al:: The pattern of Phosphate transporter 1 genes evolutionary divergence in Glycine max L.. BMC Plant Biology 2013 13:48.

\section{Submit your next manuscript to BioMed Central and take full advantage of:}

- Convenient online submission

- Thorough peer review

- No space constraints or color figure charges

- Immediate publication on acceptance

- Inclusion in PubMed, CAS, Scopus and Google Scholar

- Research which is freely available for redistribution 